\title{
CLUSTERS MUNICIPAIS DE BIOENERGIA: UM CONTRIBUTO PARA A PREVENÇÃO DE INCÊNDIOS FLORESTAIS
}

\author{
Francesca Poggi ${ }^{1}$ \\ ANA FIRMINO ${ }^{2}$ \\ Miguel AmAdo 3
}

\begin{abstract}
RESUMO - Após o momento de choque que Portugal sofreu com o incêndio de Pedrogão Grande (2017), equacionar as dimensões e responsabilidade social da Geografia torna-se especialmente relevante na construção de respostas capazes de assegurar a defesa das pessoas, dos bens e dos recursos naturais. Neste artigo reflecte-se sobre uma relação causa-efeito-solução a estabelecer para a prevenção de incêndios florestais que articula a geografia da energia com o planeamento municipal. Trata-se de uma reflexão crítica sobre a dimensão estratégica do planeamento, materializada no Plano Director Municipal e os possíveis contributos do aproveitamento e valorização da biomassa florestal, com vista ao desenvolvimento de clusters municipais ligados à bioenergia. É aqui que os mecanismos de limpeza e recolha de resíduos florestais para a produção de energia renovável emergem como valência económica indispensável para um maior contributo na prevenção activa do risco de incêndio, preconizando um novo eixo estratégico para a redução da sua incidência e melhorando o ordenamento do território a nível municipal.
\end{abstract}

Palavras-chave: Biomassa florestal; prevenção de incêndios; bioenergia; clusters municipais; Plano Diretor Municipal; PDM.

ABSTRACT - MUNICIPAL CLUSTERS OF BIOENERGY: A CONTRIBUTION TO FOREST FIRE PREVENTION. After the shock that Portugal suffered with the forest fires at Pedrogão Grande (2017), inspiring critical reflections on the role and social responsibility of Geography is especially relevant to develop an adequate response framework for the protection of life, goods and natural resources. This article reflects on a cause-effect-solution

Recebido: janeiro 2018. Aceite: maio 2018.

1 Investigadora do Centro Interdisciplinar de Ciências Sociais (CICS.Nova) da Faculdade de Ciências Sociais e Humanas da Universidade Nova de Lisboa, Avenida de Berna, 26-C, 1069-061, Lisboa, Portugal. E-mail: f.poggi@fcsh.unl.pt

2 Professora Catedrática e Investigadora Efetiva do Centro Interdisciplinar de Ciências Sociais (CICS.Nova) da Faculdade de Ciências Sociais e Humanas da Universidade Nova de Lisboa, Avenida de Berna, 26-C, 1069-061, Lisboa, Portugal. E-mail: am.firmino@fcsh.unl.pt

3 Professor Associado e Investigador Efectivo do Civil Engineering Research and Innovation for Sustainability (CERIS), DeCivil, do Instituto Superior Técnico, Avenida Rovisco Pais, 1, 1049-001, Lisboa, Portugal. E-mail: miguelpamado@tecnico.ulisboa.pt 
relationship to be established for the prevention of forest fires that articulates the geography of energy with municipal planning. It is a critical reflection on the strategic role of the Municipal Master Plan and the possible contributions that the utilization and valorization of the forest biomass can make, with the view to developing municipal bioenergy clusters. Here, cleaning and collecting forest waste for the production of renewable energy emerge as an opportunity to link energy, forest and economic benefits toward an effective fire risk prevention led by municipal decision making.

Keywords: Forest biomass; fire prevention; bioenergy; municipal clusters; Municipal Master Plan; MMP.

RÉSUMÉ - DES POLES MUNICIPAUX DE BIOENERGIE: UN INSTRUMENT CONTRE LES INCENDIES FORESTIERS. À la suite du grand incendie qui a eu lieu en 2017 dans la région de Pedrogão Grande, il est urgent que les géographes assument leur responsabilité sociale dans l'élaboration de décisions permettant la défense efficace des personnes, des biens et des ressources naturelles. On indique ici quels seraient les meilleurs rapports à établir entre la planification municipale et la Géographie de l'énergie et comment valoriser la biomasse forestière, en développant davantage la bioénergie. En particulier, les méthodes de nettoyage et de récupération des résidus forestiers sont des techniques importantes, qui fournissent des revenus permettant de mieux lutter contre les risques d'incendie, tout en améliorant la gestion du territoire à l'échelle municipale. Géographie de l'énergie, Plan de Développement Municipal, biomasse forestière, pôle municipal, prévention des incendies.

Mots clés: Biomasse forestière; prévention des incendies; bioénergie; clusters municipales; Plan de Développement Municipal; PDM.

\section{INTRODUÇÃO}

Após o momento de choque que Portugal sofreu com o incêndio de Pedrogão Grande, em 2017, equacionar as dimensões e responsabilidade social na Geografia torna-se especialmente relevante na construção de respostas capazes de assegurar a defesa das pessoas, dos bens e dos recursos naturais. $\mathrm{O}$ caso de Pedrogão Grande constitui o mais recente e violento grande incêndio verificado no País e um dos mais graves a nível mundial. A perspectiva de base científica é, contudo, a de que se está perante um tipo de catástrofe recorrente. Desde o incêndio da Serra de Sintra, em 1966, até ao da Madeira, em 2016, a problemática dos incêndios florestais tem vindo a marcar lugares, pessoas e recursos naturais tornando-se, cada vez mais, uma constante.

Não é objectivo deste artigo procurar respostas absolutas, mas sim contribuir para equacionar caminhos que até à data não tenham ainda sido implementados. O raciocínio subjacente a esta posição apoia-se na necessidade de entender que parte da solução se encontra no desenvolvimento de sistemas de prevenção dos incêndios (Ferreira et al., 2015) e na implementação de acções concretas ao nível do território (Moreira, Catry, Silva, \& Rego, 2010). É neste domínio que a limpeza de matos, a limpeza e beneficiação de caminhos e criação de zonas de descontinuidade impõe uma visão integrada ao nível municipal (ICNF, 2006). 
Mas um tal contexto torna necessário procurar perspectivas estratégicas orientadas para a implementação à escala local de acções de prevenção dependentes de investimentos (Manolis, Zagas, Poravou, \& Zagas, 2016). Este pressuposto é ainda mais justificável se se considerar que há vários elementos no caso português que dificultam a gestão da floresta: população envelhecida e com baixos níveis de formação, propriedade privada baseada no minifúndio, o que dificulta o planeamento integrado do espaço florestal, absentismo e inexistência de cadastro florestal o que, por sua vez, inviabiliza o recurso aos apoios europeus (Salvador, Pimentel, Martins, \& Fernandes, 2005).

Perante este contexto e numa postura de precaução deve ser também equacionado o cenário de alterações climáticas e os efeitos associados que se perspectivam agravados e que aumentam o risco de incêndios florestais, em particular nos países do sul da Europa (Russo et al., 2017). São estes entendimentos que evidenciam a necessidade de existir um modelo económico e financeiro que possibilite a implementação das estratégias de prevenção contra os incêndios acompanhado por um raciocínio estratégico no planeamento municipal para coordenar a sua execução e monitorização.

Com este objectivo presente, o aproveitamento da biomassa florestal como fonte de energia renovável, pode-se revelar uma oportunidade de valorização do mundo rural através da produção de energia limpa para satisfazer a demanda de energia no local (Krajačić, Duić, \& Carvalho, 2011), a melhoria da gestão das explorações (Shivan \& Mehmood, 2010) e a criação de emprego numa óptica de fileira florestal (Sacchelli, De Meo, \& Paletto, 2013). É neste sentido que o aproveitamento energético da biomassa associado a mecanismos de limpeza e recolha de resíduos florestais para a redução do risco de incêndios, leva à presente proposta de clusters municipais ligados à bioenergia.

\section{BIOENERGIA: ALGUNS CONCEITOS BÁSICOS}

\section{Conceitos básicos}

Os aspectos técnicos e logísticos que caracterizam o domínio da bioenergia e a sua relação com o planeamento municipal requerem a sistematização de alguns conceitos básicos, a começar pela definição de biomassa e a classificação das suas diferentes formas de valorização energética. Se atendermos à directiva europeia relativa à promoção da utilização de energia proveniente de fontes renováveis, a biomassa corresponde a "fracção biodegradável de produtos, resíduos e detritos de origem biológica provenientes da agricultura (incluindo substâncias de origem vegetal e animal), da exploração florestal e de indústrias afins, incluindo da pesca e da aquicultura, bem como a fracção biodegradável dos resíduos industriais e urbanos" (Parlamento Europeu, 2009, Art. $2^{\circ}$. alínea e). Neste sentido, a biomassa insere-se no quadro funcional de quatro grandes sectores: 1 . agricultura; 2 . pecuária; 3 . floresta; 4 . tratamento de resíduos resultantes da actividade humana.

De referir que o termo biomassa é abrangente e deve ser associado ao conceito de fonte de energia, ou seja, as diferentes matérias-primas para a sua produção. Por outro 
lado, a designação correcta para o tipo de energia produzida é Bioenergia, sendo este, o termo a utilizar de forma a não causar qualquer confusão com os diferentes recursos que são matéria-prima por si só ou parte de um produto compósito (Boyle, 2012). O quadro I sistematiza as diferentes categorias das fontes primárias e secundárias de biomassa, referindo alguns aspectos que são entendidos como fundamentais para a produção da bioenergia e a sua implementação no território.

Quadro I - Fontes primárias e secundárias de biomassa.

Table I - Primary and secondary biomass sources.

\begin{tabular}{llclc}
\hline \multicolumn{1}{c}{ Categoria } & \multicolumn{1}{c}{ Origem } & $\begin{array}{c}\text { Resistência clima, } \\
\text { pragas doença }\end{array}$ & \multicolumn{1}{c}{ Exemplos } & $\begin{array}{c}\text { Produção } \\
\text { média } \\
\text { (tms/ha)* }\end{array}$ \\
\hline $\begin{array}{l}\text { Biomassa } \\
\text { lenhosa }\end{array}$ & $\begin{array}{l}\text { Culturas florestais } \\
\text { Resíduos florestais }\end{array}$ & Elevada & $\begin{array}{l}\text { Eucalipto; Salgueiro; } \\
\text { Choupo }\end{array}$ & 10 \\
\hline $\begin{array}{l}\text { Biomassa } \\
\text { celulósica }\end{array}$ & Culturas energéticas agrícolas & Média & $\begin{array}{l}\text { Cardo; Miscanthus; } \\
\text { Kenaf; Painço }\end{array}$ & $10-18$ \\
\hline $\begin{array}{l}\text { Biomassa de } \\
\text { amido/açúcar }\end{array}$ & $\begin{array}{l}\text { Culturas energéticas agrícolas } \\
\text { Resíduos agrícolas }\end{array}$ & Baixa & $\begin{array}{l}\text { Cereais (milho, trigo, } \\
\text { sorgo, arroz); Beterraba; } \\
\text { Cana-de-açúcar }\end{array}$ & 10 \\
\hline $\begin{array}{l}\text { Biomassa de } \\
\text { óleos }\end{array}$ & Culturas energéticas agrícolas & Baixa & $\begin{array}{l}\text { Oleaginosas (colza, } \\
\text { girassol, soja) }\end{array}$ & 8 \\
\hline $\begin{array}{l}\text { Biomassa } \\
\text { gasosa }\end{array}$ & $\begin{array}{l}\text { Resíduos orgânicos } \\
\text { Resíduos agrícolas } \\
\text { Resíduos de origem animal }\end{array}$ & - & $\begin{array}{l}\text { Aterros sanitários; } \\
\text { ETAR; RSU; Explorações } \\
\text { agro-pecuárias }\end{array}$ & - \\
\hline
\end{tabular}

* Toneladas de matéria seca por hectare.

Fontes: Brás, Miranda, Hipólito, \& Dias (2006); ICNF, (2010a); Boyle, (2012)

A biomassa lenhosa está directamente associada às florestas, valorizando as matérias-primas produzidas por culturas florestais para fins energéticos, os resíduos resultantes das operações de limpeza dos povoamentos florestais e os resíduos/desperdícios provenientes dos processos de produção da indústria da madeira (Andrews \& Jelley, 2007). Os sistemas praticados para as culturas lenhosas são florestas de rápido crescimento com espécies dedicadas ao regime de curta rotação (ciclos de cortes cada 8-20 anos) e as plantações exploradas em regime de talhadia (ciclos de cortes cada 1-4 anos) (Boyle, 2012).

Apesar de representar um recurso com efeitos positivos nos domínios da bioeconomia, biodiversidade e preservação da qualidade dos solos, o desenvolvimento de culturas de floresta dedicadas a fins energéticos na União Europeia tem tido uma expansão bastante lenta, ao contrário do que está a acontecer ao nível internacional (Schulze, Gawel, Nolzen, Weise, \& Frank, 2016). Este facto prende-se quer pela incerteza associada à volatilidade dos preços, rendimentos incertos e custos de produção, quer pelo longo período de afectação dos solos que inviabiliza os processos de adaptação às dinâmicas dos mercados (Schulze et al., 2016).

A combinação de matéria-prima proveniente da limpeza da floresta, das atividades ligadas à fileira do sector da madeira e das culturas florestais dedicadas para a produção de energia certamente desempenhará um papel importante na transição para uma eco- 
nomia de baixo teor de carbono (Mola-Yudego et al., 2017). Assim sendo, é relevante mencionar as espécies energéticas mais comuns para a criação de florestas de rápido crescimento e que podem ser adaptadas ao território português, nomeadamente o choupo, o salgueiro e o eucalipto (Lindegaard et al., 2016).

No seguimento do que se referiu anteriormente, considera-se essencial salientar o modo como a implementação da bioenergia poderá evoluir no contexto nacional. Neste âmbito, as avaliações efectuadas por vários estudos apontam para um potencial de biomassa total estimado de $34097 \mathrm{GWh} /$ ano, dividido de acordo com os recursos da figura 1 (Ferreira, Monteiro, Brito, \& Vilarinho, 2017).

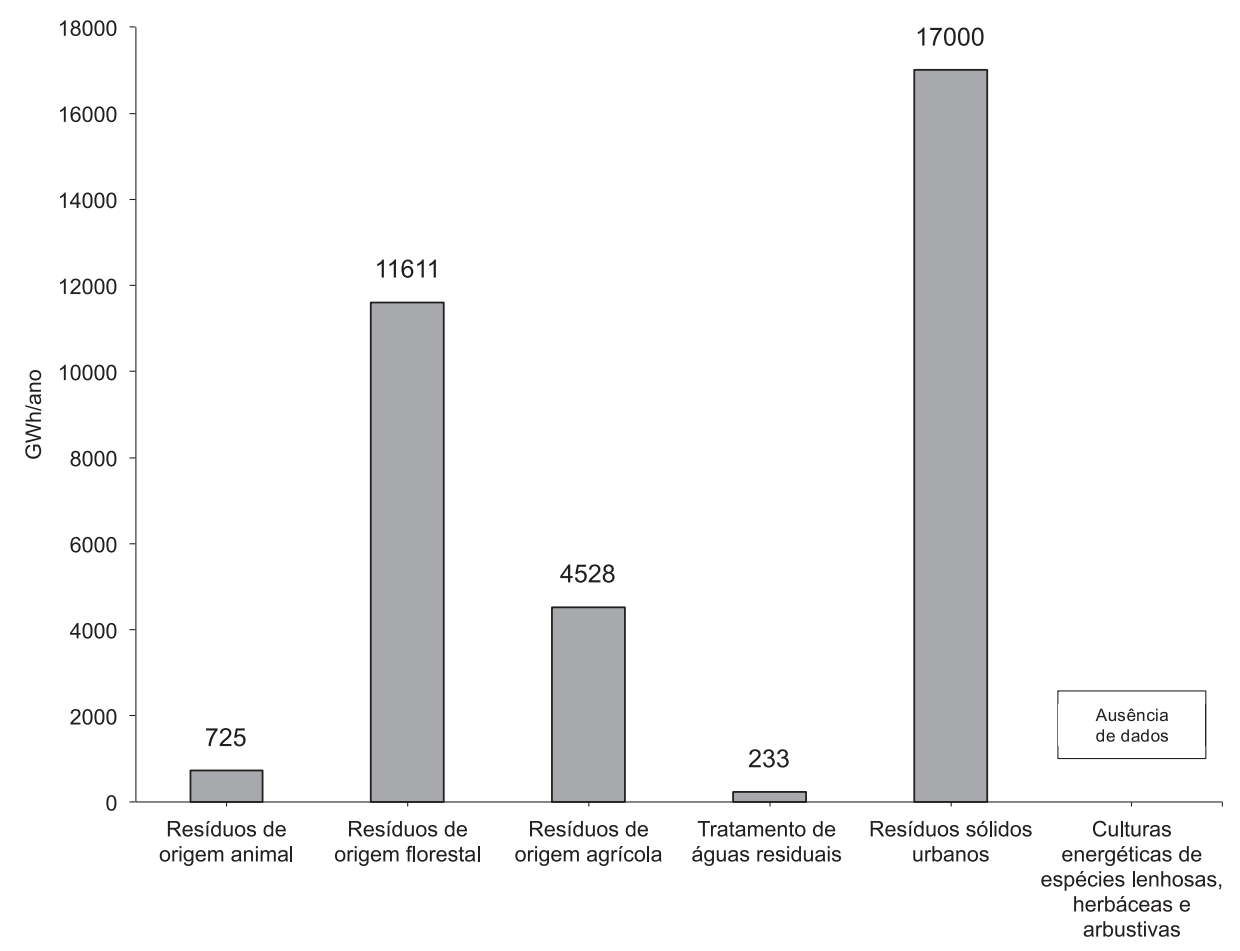

Fig. 1 - Contribuição potencial dos diferentes recursos de biomassa à escala nacional.

Fig. 1 - Potential contribution of different biomass resources at the national scale.

Fonte: Adaptado de Ferreira et al. (2017)

Focando no potencial de matéria-prima decorrente das florestas, é importante salientar a ausência de dados que permitam estimativas das culturas energéticas de espécies lenhosas, herbáceas e arbustivas, sendo um indicador do facto que actualmente não existe produção regular destas culturas em Portugal (ICNF, 2010b). Por outro lado, o contributo dos diversos recursos ilustrado na figura 1 , constitui um referencial que justifica identificar os resíduos de origem florestal como o principal sector com potencial em termos de disponibilidade da matéria-prima, viabilidade ambiental e económica e competitividade. De facto, este recurso assume especial importância em Portugal, porquanto $38 \%$ da área do território nacional é coberto por floresta (ICNF, 2010b). Em termos de valorização energética, Viana, Cohen, Lopes, Aranha, (2010) estimaram que a quantidade total de biomassa é em torno de 1097 milhão t/ano, sendo 579,91 mil t/ano de pinheiro-bravo (em peso seco). 


\section{Enquadramento legal de utilização da biomassa em Portugal}

A diversidade das diferentes fontes de biomassa e a sua distribuição geográfica extensa e dispersa, bem como a sua variabilidade ao longo do tempo, obriga a interpelar o território enquanto suporte físico e logístico, local de limpeza, de produção de energia renovável e, como tal, um sistema onde se deve desenvolver uma acção ao nível da prevenção dos incêndios, que pretendemos analisar. A necessidade de uma análise crítica acerca do impacto da legislação na valorização energética da biomassa, torna-se uma etapa essencial para entender o actual quadro de implementação global deste recurso.

Neste sentido, começa-se por mencionar o Plano Nacional de Defesa da Floresta contra Incêndios (PNDFCI), aprovado pela Resolução do Conselho de Ministros n. ${ }^{\circ}$ 65/2006, de 26 de Maio, que preconizou intervenções em domínios prioritários como sejam a prevenção estrutural, vigilância, combate e eixos estratégicos de atuação, envolvendo, nomeadamente, o aumento da resiliência do território aos incêndios florestais, a redução da incidência dos incêndios, a melhoria da eficácia do ataque e da gestão dos incêndios, a recuperação e reabilitação dos ecossistemas e a adaptação de uma estrutura orgânica e funcional eficaz. Este conjunto de medidas representou um primeiro passo importante no equacionar a biomassa para energia como um possível contributo na prevenção dos incêndios e valorização das florestas.

É de facto, na sequência do disposto pelo PNDFCI, que o Governo lançou no mesmo ano a Estratégia Nacional para as Florestas (ENF), aprovada pela Resolução do Conselhos de Ministros no 114/2006, de 15 de setembro de 2006, que reconheceu a importância que a fileira da biomassa para energia representava para o desenvolvimento nacional e destacou o valor dos recursos florestais para a sociedade nas suas diversas funções e valências económicas, sociais e ambientais (Soares \& Tavares da Silva, 2013).

Ainda que assumindo alguma coincidência e complementaridade dos objectivos da ENF, a Estratégia Nacional para a Energia aprovada pela Resolução do Conselho de Ministros n. ${ }^{\circ}$ 29/2010, de 15 de abril de 2010, veio reforçar a elevada importância da valorização energética da biomassa para o País considerando a sua transversalidade à gestão florestal na redução dos riscos associados, nomeadamente incêndios, bem como para a sua sustentabilidade. É neste documento que se começa também a referir a oportunidade de criar riqueza e consolidar um cluster energético no sector das energias renováveis em Portugal, conceitos estes, que assumem particular relevância no âmbito da proposta de modelo que se apresenta neste estudo. A necessidade de articular estas duas estratégias foi reconhecida na Resolução do Conselhos dos Ministros no 81/2010, de 3 de novembro de 2010, que veio estabelecer algumas medidas destinadas a incentivar a produção de biomassa florestal em Portugal. Os pontos a destacar neste documento são em primeiro lugar, efectivar a construção e exploração das centrais de biomassa florestal, relativas ao concurso lançado em 2006, bem como de outras já licenciadas e que ainda não iniciaram a sua implementação, até o final de 2013, associando ao cumprimento destes objectivos a aplicação de um incentivo económico. Em segundo lugar, assegurar a sustentabilidade a prazo do abastecimento das centrais dedicadas a biomassa prevendo a possibilidade de plantação de culturas dedicadas, ou sejam, de árvores e arbustos com 
características de crescimento rápido. Em terceiro lugar, promover os restos florestais resultantes das limpezas das florestas e matas como uma das matérias-primas essenciais destas centrais de produção de energia, visando-se dinamizar as operações de limpeza destas áreas e contribuindo de forma significativa para a prevenção dos fogos florestais.

Em termos práticos, foi o Decreto-Lei (DL) no 5/2011, de 10 de janeiro de 2011, que veio dar desenvolvimento às medidas anteriormente referidas, aplicando-se às centrais dedicadas a biomassa florestal relativas aos concursos públicos lançados em 2006, bem como àquelas cuja autorização de instalação se encontrasse atribuída. No entanto, os atrasos registados na instalação de muitas das centrais abrangidas por este DL determinaram duas alterações dos prazos fixados para beneficiar dos incentivos económicos associados a entrada em exploração, que passou do final de 2016 para o final de 2018.

Para o efeito, a nova legislação produzida e revista no âmbito da recente reforma florestal tem preconizado um impulso que poderá ser decisivo para a mudança de paradigma a qual o País está a ser chamado, assumindo maior importância após os grandes incêndios de 2017 (ICNF, 2017). Neste âmbito é de referir o DL n. ${ }^{\circ}$ 64/2017, de 12 de junho, que define um regime especial e extraordinário para a instalação e exploração, por municípios, de novas centrais de valorização de biomassa, definindo, ao mesmo tempo, medidas de apoio e incentivo destinadas a assegurar a sua concretização, com o objetivo fundamental da defesa da floresta, do ordenamento e preservação florestais, e do combate aos incêndios.

A passagem ao nível local constitui um aspecto chave para se entender o novo papel que os municípios devem ter na dinamização de iniciativas relacionadas com a biomassa florestal para energia. Neste quadro, o DL n. ${ }^{\circ} 65 / 2017$, de 12 de junho, veio salientar a necessidade de adaptação dos Planos Diretores Municipais (PDM) face ao conteúdo dos Programas Regionais de Ordenamento Florestal envolvendo, obrigatoriamente, a atualização das respetivas plantas de ordenamento e de condicionantes. Esta perspectiva põe em evidência a importância da gestão adequada dos recursos de biomassa florestal e, com ela, a de capacitar as autarquias na conceptualização de abordagens com finalidade de acção, seja no âmbito da identificação e caracterização de meios/instrumentos a utilizar, bem como de elaboração de medidas de base territorial adequadas ao seu contexto económico, ambiental e social.

É neste sentido que a relação causa-efeito-solução a estabelecer, articula a questão do aproveitamento da biomassa para a produção de energia renovável e a mitigação do risco de incêndios com o planeamento municipal. A reflexão crítica sobre o quadro legal que tem surgido na sequência do incêndio de Pedrogão Grande, a dimensão estratégica no planeamento local, materializada pelo PDM e os possíveis contributos do aproveitamento e valorização da biomassa florestal, toma então um lugar central com vista ao desenvolvimento de clusters municipais ligados à bioenergia.

\section{CLUSTERS MUNICIPAIS DA BIOENERGIA}

A abordagem de cluster, baseada no conceito de "concentração geográfica num particular núcleo de território de empresas inter-relacionadas e instituições correlatas tais como entidades públicas, universidades ou associações empresariais que competem 
mas também colaboram no âmbito de determinado sector" (Porter, 2000, p. 15), constitui um discurso de desenvolvimento territorial e económico particularmente relevante para a realidade portuguesa. As potenciais vantagens competitivas associadas à teoria dos clusters, assentam na optimização de quatro aspectos fundamentais que constituem o modelo de Diamante de Porter: a condição dos fatores de produção; a condição da procura dos produtos/serviços; a existência de indústrias relacionadas e de apoio e a estratégia, estrutura e rivalidade das empresas (Porter, 1990). Assim sendo, está-se perante um modelo cuja natureza sistémica visa a criação de um contexto para a promoção de clusters de indústrias competitivas (Porter, 1990). Neste sentido, explorar um conceito de "clusters municipais da bioenergia" significa operar uma adaptação do modelo Porter, promovendo a constituição de task forces entre municípios para implementar um sistema cooperativo, competitivo e economicamente rentável para a prevenção de incêndios florestais. Esta perspectiva posiciona-se de forma complementar em relação ao ordenamento do território, incidindo sobre a gestão, preservação e monitorização das florestas através de estratégias e regras associadas ao PDM, que o tornem eficaz. Assim, no cerne do modelo aqui proposto está o factor económico suportado por um quadro que articula o planeamento estratégico no PDM, a implementação e monitorização constante em cada município e a autonomia da execução financeira garantida pela produção de energia renovável.

Apresenta-se de seguida um exemplo exploratório de aplicação do modelo cluster, considerando o município de Pampilhosa da Serra onde os incêndios de 2017 afetaram uma área de $20000 \mathrm{ha}$ de floresta, num total de $35300 \mathrm{ha}$. Ocupando uma área de $397 \mathrm{~km}^{2}$ e possuindo uma população residente de 4257 habitantes (INE, 2013), Pampilhosa da Serra distingue-se pela homogeneidade do seu território e actividades humanas aí desenvolvidas. Neste contexto, é de salientar que se está perante um concelho marcado por uma superfície de áreas florestais que representa mais de $88 \%$ do seu território (fig. 2).

A forte componente de actividades ligadas à silvicultura, com relevo para as culturas de Eucalipto, Medronheiro e Pinheiro Bravo, constituem o principal vector de desenvolvimento económico do concelho. Tendo em conta esta concisa descrição do município em análise, os objectivos estratégicos de desenvolvimento de um cluster municipal da bioenergia prendem-se com a elevada incidência de incêndios e da oportunidade de localizar no concelho uma central de biomassa para auxiliar as operações de limpeza da floresta envolvendo a escala local e intermunicipal. Neste quadro, a área de abrangência teórica do cluster de bioenergia está associada à própria área de influência de uma central de biomassa. De acordo com o estudo desenvolvido por Viana et al. (2010), adoptou-se um raio de recolha de cerca de $35 \mathrm{~km}$ que, desenhado a partir do centróide do Concelho, envolve, além de Pampilhosa da Serra, outros municípios de índole morfológica similar (fig. 3).

A delimitação do cluster municipal de bioenergia, representa um exemplo de contexto territorial adequado para operacionalizar estratégias de prevenção de incêndios e gestão florestal, relacionadas com a valorização energética da matéria-prima obtida e explorar sinergias entre municípios e investidores privados para a implementação de uma central de biomassa. 

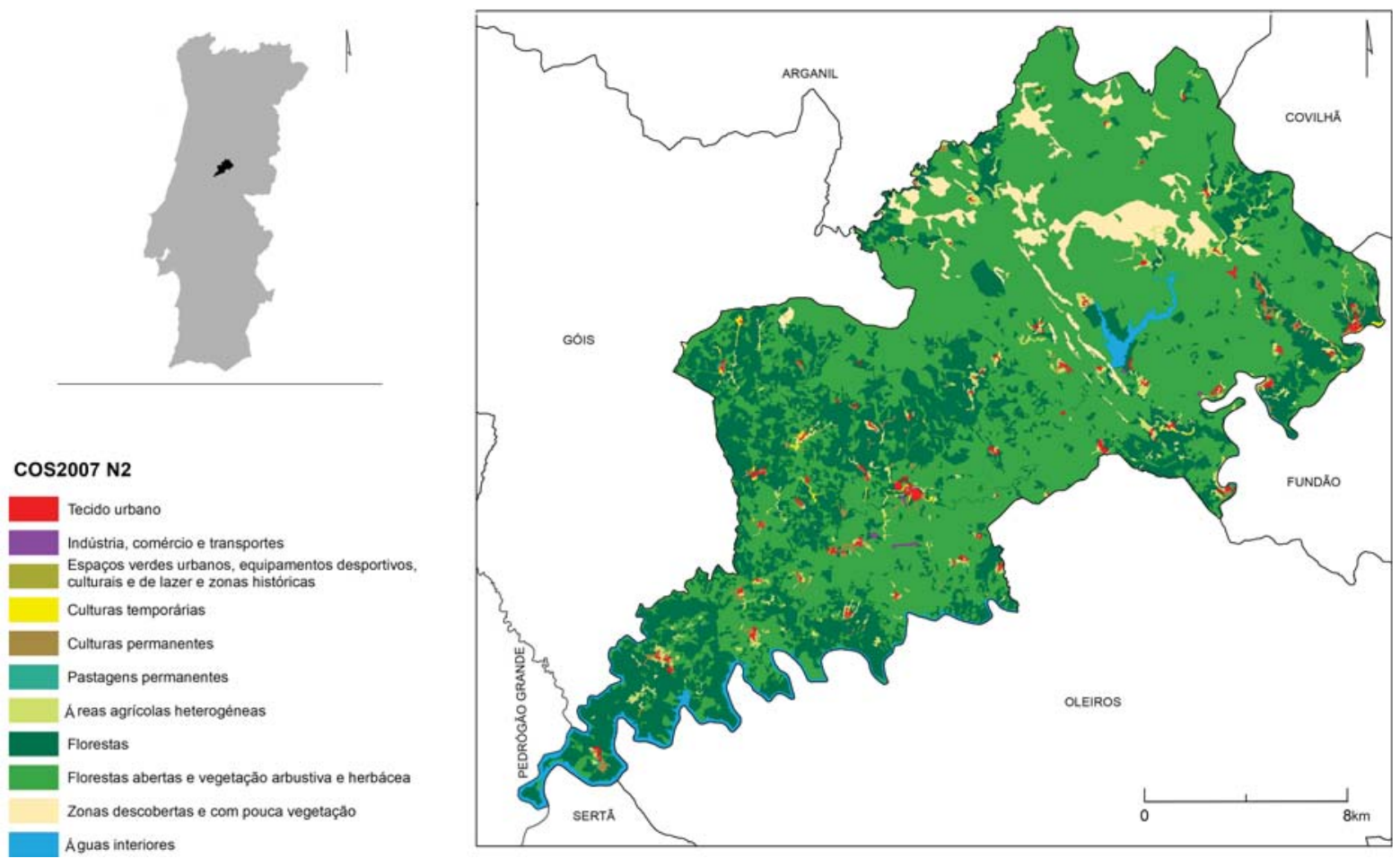

Fig. 2 - Padrões de uso e ocupação do solo no concelho de Pampilhosa da Serra.

Figura a cores disponível online.

Fig. 2 - Main patterns of land use and land cover in the municipality of Pampilhosa da Serra.

Colour figure available online.

Fonte: baseado na Carta de Uso e Ocupação do Solo (COS2007, nível 2)

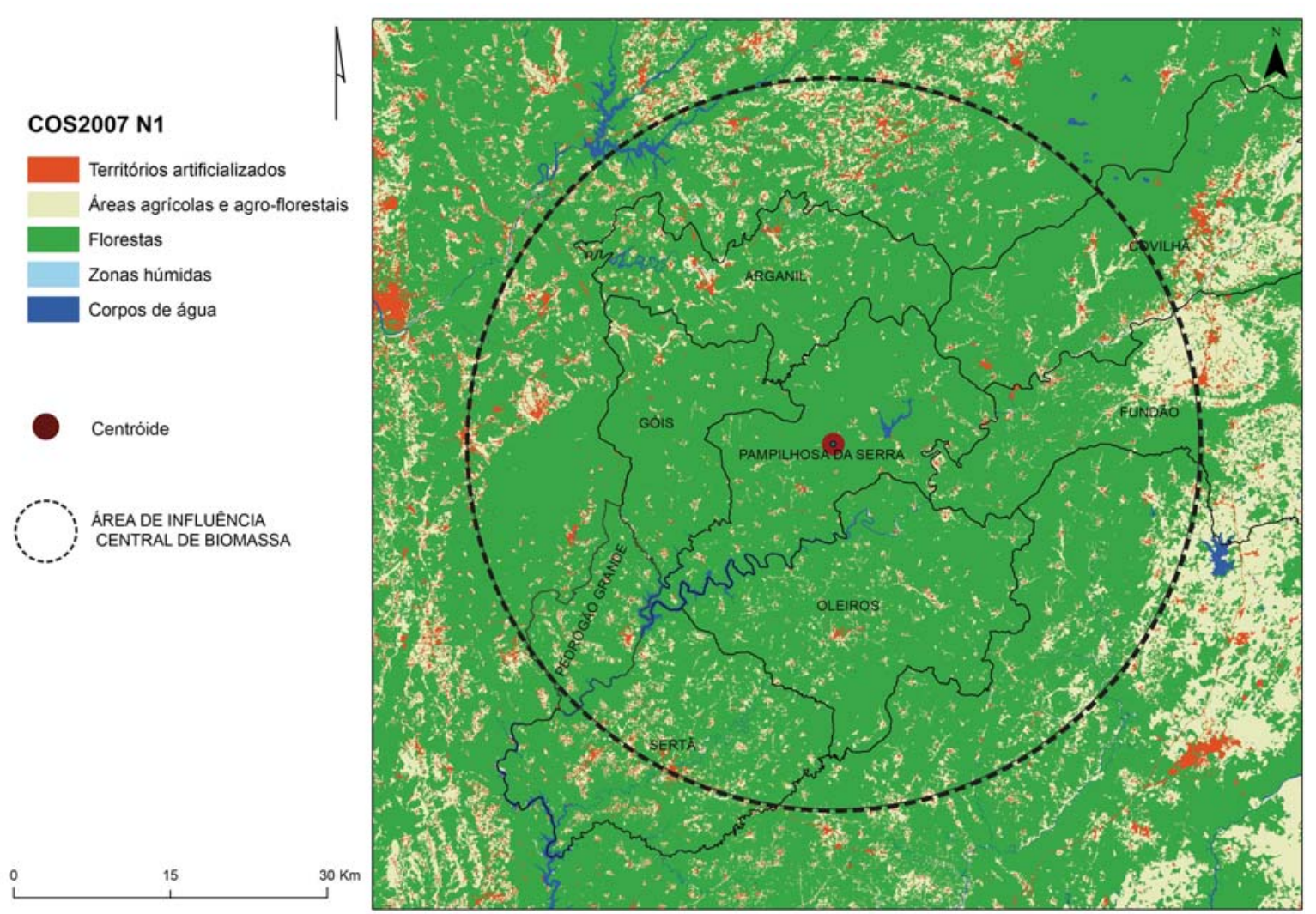

Fig. 3 - Exemplo de delimitação de cluster municipal de bioenergia. Figura a cores disponível online.

Fig. 3 - Example of municipal bioenergy cluster delimitation. Colour figure available online. 
Em termos gerais, as componentes fundamentais desta abordagem são constituídas pelas seguintes vertentes:

1. atracção de investimento privado - decorre da realização de centrais de biomassa com uma abrangência municipal ou intermunicipal. É o domínio onde se geram e consubstanciam as regras de localização destas infra-estruturas, com suporte em modelos de Sistemas de Informação Geográfica capazes de identificar espacialmente e contribuir para quantificar o potencial de biomassa existente e disponível para recolha num município;

2. criação de emprego no sector público - a necessidade de remover e recolher os resíduos florestais no interior do território municipal traduz-se numa oportunidade de criação de emprego localizado. Na lógica de cluster municipal de bioenergia está implícita a criação de empresas municipais ou intermunicipais associadas às actividades de manutenção e monitorização da floresta;

3. controlo da ocupação do solo privado e público - considerando a limpeza e manutenção da floresta como um aspecto prioritário, colectivo e de responsabilidade social, o PDM deve assumir-se como ferramenta para a estratégia de programação da limpeza, tanto em solo privado como público. No caso da propriedade privada, a limpeza pode ser realizada através de dois mecanismos: existência de incentivo económico ao proprietário ou determinação de procedimentos de acção de segurança pública a serem introduzidos ao nível das Unidades Operativas de Planeamento e Gestão, a que os privados devem garantir o cumprimento nas suas acções de uso e transformação do solo. O incentivo económico prevê estimular os proprietários a fazerem a limpeza dos próprios terrenos e esse apoio económico está interligado com a entrega dos respectivos resíduos na central de biomassa mais próxima para que se operacionalize o incentivo. Por outro lado, nos casos em que o proprietário é desconhecido ou não tem recursos para efetuar a própria limpeza, será o sector público, através do serviço municipal, a efectuar a limpeza na propriedade privada ao abrigo de uma acção por razões de segurança pública, arrecadando este o valor do incentivo económico equivalente;

4. criação de serviços municipais para a prevenção dos incêndios florestais - a produção de bioenergia tem como vantagem a geração de valor decorrente da venda da energia, valor esse a distribuir territorialmente em suporte dos serviços de coordenação, limpeza e recolha dos resíduos florestais e monitorização do território. A aplicação deste modelo origina um conjunto de domínios de intervenção capazes de promover sinergias entre uso inteligente do solo, produção de bioenergia e prevenção de incêndios (quadro II). 
Quadro II - Clusters municipais de energia: principais domínios de intervenção.

Imagem a cores disponível online.

Table II - Municipal clusters of energy: main domains of intervention.

Colour image available online.

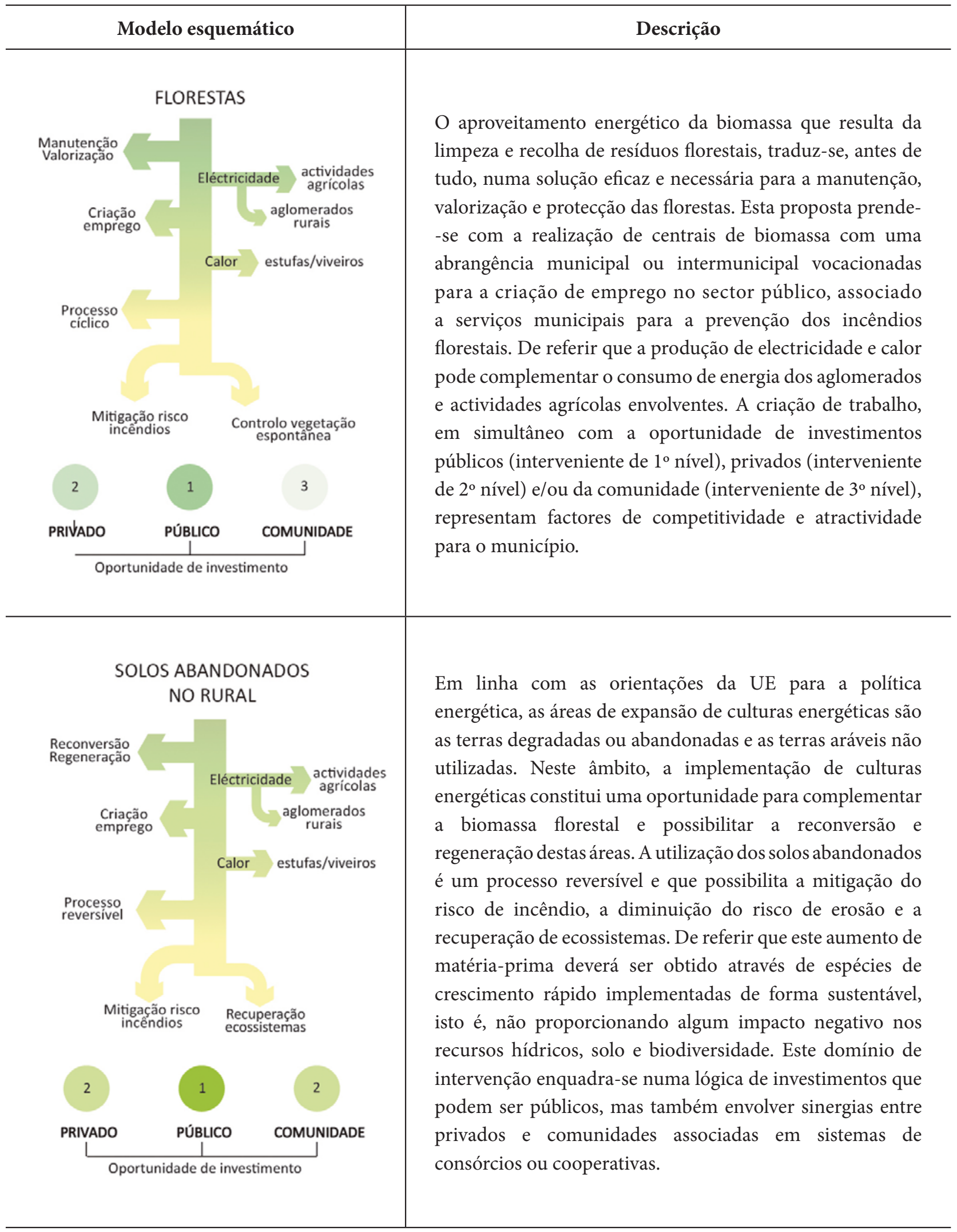


Quadro II - (cont.).

Table II - (cont.).

\begin{tabular}{|c|c|}
\hline Modelo esquemático & Descrição \\
\hline 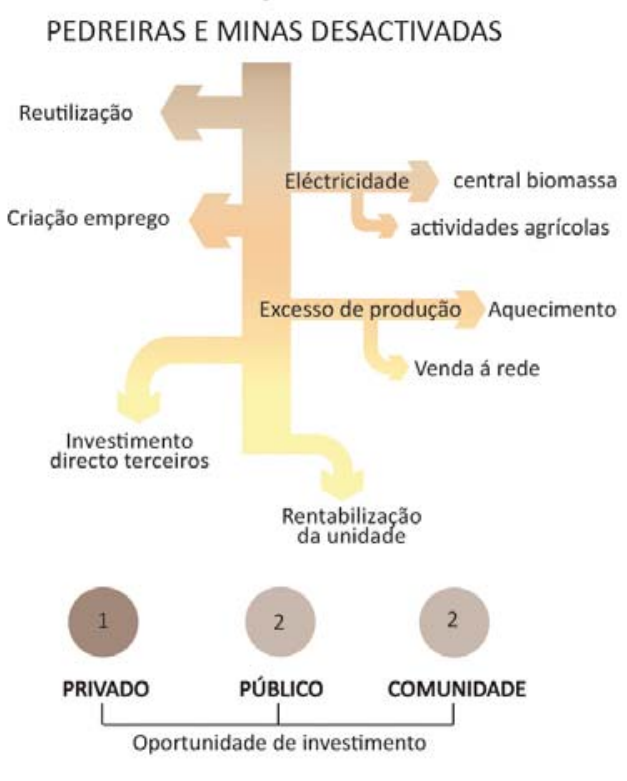 & $\begin{array}{l}\text { A produção de bioenergia coloca a questão da implantação } \\
\text { das respectivas centrais a biomassa. Trata-se de um tipo de } \\
\text { equipamento cuja localização e dimensão representam } \\
\text { aspectos fundamentais para garantir a logística associada } \\
\text { com a recolha, entrega e armazenamento de matéria prima. } \\
\text { De referir a necessidade de manter estas centrais afastadas } \\
\text { dos aglomerados para evitar eventuais emissões de poluentes } \\
\text { e maus cheiros. Neste sentido, as pedreiras e as minas } \\
\text { desactivadas, sendo habitualmente afastadas de qualquer } \\
\text { aglomerado urbano e rural, constituem localizações óptimas } \\
\text { para este tipo de central. A própria configuração espacial } \\
\text { apresenta áreas adequadas para o armazenamento de } \\
\text { grandes quantidades de matéria prima. Acrescenta-se a } \\
\text { possibilidade de associar à produção de bioenergia, a } \\
\text { instalação de painéis fotovoltaicos nas áreas envolventes } \\
\text { com encostas e declives que apresentem boa exposição solar. }\end{array}$ \\
\hline
\end{tabular}

As propostas de intervenção desenvolvidas no âmbito do presente estudo, referem-se ao aproveitamento da biomassa florestal complementado, ou não, por culturas energéticas em solos abandonados, destacando-se os respectivos benefícios ambientais, sociais e económicos. De acordo com os três modelos esquemáticos apresentados, ressalta que a implementação da bioenergia necessita de ser associada a uma abordagem integrada e sectorial que permita o seu aproveitamento de forma sustentável. Dando suporte à necessidade de um planeamento da bioenergia à escala municipal, é também apresentado um modelo que representa uma orientação concreta para a localização das centrais a biomassa aproveitando as áreas de pedreiras ou minas desactivadas. Por fim, é de referir que numa óptica de valorização do interesse público e da responsabilidade civil, a promoção da biomassa para energia coloca-se não como um custo, mas antes, como uma oportunidade de investimento para o sector privado, público e comunidades locais, como se evidencia no âmbito de cada esquema apresentado.

\section{CONCLUSÕES}

A natureza complexa e em parte imprevisível, que decorre da problemática dos incêndios florestais, não permite respostas lineares e imediatas, em particular no contexto de territórios de baixa densidade caracterizado pela escassez de recursos humanos e financeiros. Da análise apresentada, emerge que é do território, sociedade e economia que estamos a falar: da necessidade de encontrar soluções eficazes e mais resilientes de ordenamento do território, necessidade de incorporar o interesse pela 
segurança pública e responsabilidade partilhada e a necessidade de criar modelos económicos que conduzam à implementação das acções. É com este conjunto de premissas que os mecanismos de limpeza e recolha de resíduos florestais para produção de energia renovável, emergem como valência económica indispensável a um maior contributo na diminuição activa do risco de incêndio, indicando um novo eixo estratégico para a redução da sua incidência e melhorando o ordenamento do território a nível municipal. A proposta de clusters municipais de bioenergia visa suscitar a cooperação entre municípios contíguos com gestão e intervenção num mesmo tipo de território. Esta proposta decorre da assunção do principal valor que estrutura e mobiliza a sociedade moderna: o valor económico, sem contudo deixar de reconhecer a necessidade de defesa da floresta como um bem comum do país, à luz de uma justiça territorial, um direito social e uma responsabilidade colectiva.

\section{AGRADECIMENTOS}

Agradece-se à Fundação para a Ciência e a Tecnologia a bolsa de doutoramento concedida à primeira autora (referência SFRH/BD/94702/2013).

\section{REFERÊNCIAS BIBLIOGRÁFICAS}

Andrews, J., \& Jelley, N. (2007). Energy Science: Principles, Technologies, and Impacts. Oxford, New York: Oxford University Press.

Boyle, G. (2012). Renewable energy: power for a sustainable future. Open University ( $3^{\mathrm{a}}$.). Oxford: Oxford University Press.

Brás, A. M., Miranda, F., Hipólito, L., \& Dias, L. S. (2006). Biomassa e produção de energia [Biomass and energy production] [Versão eletrónica]. In Direcção Regional de Agricultura de Entre Douro e Minho (Eds.), O Minho, a Terra e o Homem [The Minho, the Earth and the Man] (pp. 23-30). Retrieved from http://docplayer.com.br/9358312 -Biomassa-e-producao-de-energia.html

Decreto-Lei n. ${ }^{\circ}$ 64/2017, de 12/06/2017 - Aprova o regime para novas centrais de biomassa florestal [Approves the regime for new forest biomass power stations]. Retrieved from http://data.dre. pt/eli/dec-lei/64/2017/06/12/p/dre/pt/html

Decreto-Lei n. ${ }^{\circ}$ 65/2017, de 12/06/2017 - Altera o regime jurídico dos planos de ordenamento, de gestão e de intervenção de âmbito florestal [Amends the legal regime of forest management, management and intervention plans]. Retrieved from http://data. dre.pt/eli/dec-lei/65/2017/06/12/p/dre/pt/html
Decreto-Lei n. ${ }^{\circ}$ 5/2011, de 10/01/2011 - Produção e Aproveitamento de Biomassa Florestal [Production and Use of Forest Biomass]. Retrieved from http://data.dre.pt/eli/dec-lei/5/2011/01/10/p/ $\mathrm{dre} / \mathrm{pt} / \mathrm{html}$

Ferreira, A. J. D., Alegre, S. P., Coelho, C. O. A., Shakesby, R. A., Páscoa, F. M., Ferreira, C. S. S... Ritsema, C. (2015). Strategies to prevent forest fires and techniques to reverse degradation processes in burned areas. CATENA, 128, 224-237.

Ferreira, S., Monteiro, E., Brito, P., \& Vilarinho, C. (2017). Biomass resources in Portugal: Current status and prospects. Renewable and Sustainable Energy Reviews, 78, 1221-1235.

Shivan, G. C., \& Mehmood, S. R. (2010). Factors influencing nonindustrial private forest landowners policy preference for promoting bioenergy. Forest Policy and Economics, 12(8), 581-588.

Instituto da Convervação da Natureza e das Florestas. (ICNF). (2017). Relatório provisório de incêndios florestais 2017 [Provisional report on forest fires 2017]. Lisboa: Instituto da Conservação da Natureza e das Florestas. Retrieved from http:// www2.icnf.pt/portal/florestas/dfci/Resource/ doc/rel/2017/10-rel-prov-1jan-31out-2017.pdf 
Instituto da Convervação da Natureza e das Florestas. (ICNF). (2010a). Culturas Energéticas Florestais [Forest energy crops]. Lisboa: Instituto da Conservação da Natureza e das Florestas. Retrieved from http://www.icnf.pt/portal/florestas/fileiras/ resource/docs/biom/biomass-gtce-jun10

Instituto da Conservação da Natureza e das Florestas. (ICNF). (2010b). 5. Inventário Florestal Nacional [ $5^{\text {th }}$ Nacional Forest Inventory]. Lisboa: Instituto da Conservação da Natureza e das Florestas.

Instituto da Conservação da Natureza e das Florestas. (ICNF). (2006). Plano Nacional de Defesa da Floresta Contra Incêndios [National Forest Fire Protection Plan]. Lisboa: Instituto da Conservação da Natureza e das Florestas. Retrieved from https:// poseur.portugal2020.pt/media/4140/plano nacional_defesa_floresta_contra_incendios.pdf

Instituto Nacional de Estatística. (INE). (2013). População residente $\left(N .^{\circ}\right)$ por Local de residência. Estatísticas territoriais [Resident population ( $\mathrm{N}^{\circ}$.) by residence. Territorial statistics]. Retrieved from https://www. ine.pt/xportal/xmain?xpid=INE\&xpgid=ine unid_territorial\&menuBOUI=13707095\&context $\underline{\mathrm{o}=u t \& s e l T a b=t a b 3}$

Krajačić, G., Duić, N., \& Carvalho, M. da G. (2011). How to achieve a $100 \%$ RES electricity supply for Portugal? Applied Energy, 88(2), 508-517.

Lindegaard, K. N., Adams, P. W. R., Holley, M., Lamley, A., Henriksson, A., Larsson, S... Pisarel, M. (2016). Short rotation plantations policy history in Europe: lessons from the past and recommendations for the future. Food and Energy Security, 5(3), 125-152.

Manolis, E. N., Zagas, T. D., Poravou, C. A., \& Zagas, D. T. (2016). Biomass assessment for sustainable bioenergy utilization in a Mediterranean forest ecosystem in northwest Greece. Ecological Engineering, 91, 537-544.

Mola-Yudego, B., Arevalo, J., Díaz-Yáñez, O., Dimitriou, I., Haapala, A., Carlos Ferraz Filho, A... Valbuena, R. (2017). Wood biomass potentials for energy in northern Europe: Forest or plantations? Biomass and Bioenergy, 106, 95-103.

Moreira, F., Catry, F. X., Silva, J. S., \& Rego, F. (2010). Ecologia do fogo e gestão de áreas ardidas [Fire ecology and management of burned areas]. Isapress. Retrieved from https://www.repository. utl.pt/handle/10400.5/3894

Parlamento Europeu. (2009). Directiva 2009/28/CE. Jornal Oficial da União Europeia, 140/17, 47.

Porter, M. E. (1990). The competitive advantage of nations. New York: Free Press.

Porter, M. E. (2000). Location, competition, and economic development: Local clusters in a global economy. Economic development quarterly, 14(1), 15-34.

Russo, A., Gouveia, C. M., Páscoa, P., Da Camara, C. C., Sousa, P. M., \& Trigo, R. M. (2017). Assessing the role of drought events on wildfires in the Iberian Peninsula. Agricultural and Forest Meteorology, 237-238, 50-59.

Sacchelli, S., De Meo, I., \& Paletto, A. (2013). Bioenergy production and forest multifunctionality: A trade-off analysis using multiscale GIS model in a case study in Italy. Applied Energy, 104, 10-20.

Salvador, R., Pimentel, D., Martins, F., \& Fernandes, A. (2005). Reconstrução do espaço florestal [Reconstruction of forest space]. X Colóquio Ibérico de Geografia "A Geografia Ibérica no contexto Europeu”. APGEO, Évora.

Schulze, J., Erik, G., Nolzen, H., Weise, H., \& Frank, K. (2016). The expansion of short rotation forestry: characterization of determinants with an agentbased land use model. GCB Bioenergy, 9(6), 1042-1056.

Soares, C. A., \& Tavares da Silva, S. (2013). Direito das Energias Renováveis [Renewable Energy Law]. Coimbra: Edições Almedina.

Viana, H., Cohen, W. B., Lopes, D., \& Aranha, J. (2010). Assessment of forest biomass for use as energy. GIS-based analysis of geographical availability and locations of wood-fired power plants in Portugal. Applied Energy, 87(8), 2551-2560. 